OPEN ACCESS

Edited by:

Liliana Belgioia,

Università di Genova, Italy

Reviewed by:

Catherine Teh,

St. Luke's Medical Center, Philippines

Daniele Presti,

Institut Gustave Roussy, France

*Correspondence:

Xinxiang $L$

1149/xx@sina.com

Qingguo Li

oncosurgeonli@sohu.com

${ }^{\text {t}}$ These authors have contributed equally to this work

Specialty section:

This article was submitted to

Surgical Oncology,

a section of the journal

Frontiers in Oncology

Received: 07 March 2021 Accepted: 23 June 2021

Published: 07 July 2021

Citation:

Liu Q, Zhang R, Li Q and Li X (2021)

Clinical Implications of Nonbiological Factors With Colorectal Cancer Patients Younger Than 45 Years.

Front. Oncol. 11:677198.

doi: 10.3389/fonc.2021.677198

\section{Clinical Implications of Nonbiological Factors With Colorectal Cancer Patients Younger Than 45 Years}

\author{
Qi Liu ${ }^{1,2 \dagger}$, Ruoxin Zhang ${ }^{1,2 \dagger}$, Qingguo $\mathrm{Li}^{1,2 *}$ and Xinxiang $\mathrm{Li}^{1,2 *}$ \\ ${ }^{1}$ Department of Colorectal Surgery, Fudan University Shanghai Cancer Center, Shanghai, China, ${ }^{2}$ Department of Oncology, \\ Shanghai Medical College, Fudan University, Shanghai, China
}

Background: To evaluate the clinical implications of non-biological factors (NBFs) with colorectal cancer (CRC) patients younger than 45 years.

Methods: In the present study, we have conducted Cox proportional hazard regression analyses to evaluate the prognosis of different prognostic factors, the hazard ratios (HRs) were shown with 95\% confidence intervals (Cls). Kaplan-Meier method was utilized to compare the prognostic value of different factors with the log-rank test. NBF score was established according to the result of multivariate Cox analyses.

Results: In total, 15129 patients before 45 years with known NBFs were identified from the SEER database. Only county-level median household income, marital status and insurance status were NBFs that significantly corelated with the cause specifical survival in CRC patients aged less than 45 years old $(P<0.05)$. Stage NBF 1 showed $50.5 \%$ increased risk of $\mathrm{CRC}$-specific mortality $(\mathrm{HR}=1.505,95 \% \mathrm{Cl}=1.411-1.606, \mathrm{P}<0.001)$. Stage NBF 0 patients were associated with significantly increased CRC-specific survival (CCSS) when compared with the stage NBF 1 patients in different AJCC TNM stages.

Conclusions: NBF stage (defined by county-level median household income, marital status and insurance status) was strongly related to the prognosis of CRC patients. NBFs should arouse enough attention of us in clinical practice of patients younger than 45 years.

Keywords: non-biological factors, colorectal cancer, young, screening, prognosis

\section{INTRODUCTION}

Colorectal cancer (CRC) is one of the most common malignant tumors. The vast majority of patients with CRCs are > 50 years of age. $75 \%$ of CRC patients present with rectal cancer and $80 \%$ with colon cancer at an age higher than 60 years at the time of diagnosis (1). However, the incidence rate of CRC is increasing in young persons, the American Cancer Society (ACS) therefore recommends average-risk CRC screening at 45 years old (2).

CRC incidence rates have risen by $1.3 \%$ and $2.3 \%$ per year in patients at the age of $40-49$ years in the United States over the last two decades, respectively. On the contrast, incidence rates of patients over the age of 55 years have decreased by 2 - to 3 -fold, which is largely attributed to the screening of this disease (3). 
Recently, the ACS recommended average-risk CRC screening in adults aged $\geq 45$ years with stool-based test or a visual examination (4). It is worth noting that CRC screening before the age of 45 is still somewhat neglected, which may cause the increasing percentage of CRC patients aged less than 45 years.

The oncological outcomes of cancer patients would be affected by biological factors and non-biological factors (NBFs). The prognostic effects of different biological factors on CRC patients have been widely studied, including patient age, race, histological type, lymph node invasion, tumor grade, tumor size, gender and so on. The associations of NBFs with tumors, such as CRC, breast cancer and testicular cancer, have been reported (5-11). However, their prognostic significance was neglected to some extent (12-15).

Moreover, the widely utilized AJCC staging system is only based on the biological factors, and it is sometimes unable to accurately predict the prognosis of CRC patients. We therefore conducted this study to evaluate the implications of NBFs with staging, prognosis and clinical management of CRC patients younger than 45 years.

\section{METHODS}

\section{Patients}

The SEER-Stat software (SEER ${ }^{\star}$ Stat 8.3.8, https://seer.cancer. gov/seerstat/) was used in the present study, patients meeting the strict criteria were identified from the Surveillance,
Epidemiology and End Results (SEER) database, which is a comprehensive source of population-based information on clinicopathological features and survival of cancer patients in the USA. Initially, CRC patients aged less than 45 years old were selected from SEER 18 registries between January 1, 2007 and December 31, 2015. Subsequently, only CRC patients with known NBFs were included in the present study according to the following criteria: (1). Marital status (married or unmarried), (2). insurance status (insured, medicaid or uninsured), (3) median household income, (4). county $\%$ with bachelor degree ( $\mathrm{N}=17189)$, 5unemployment status $(\mathrm{N}=17189)$, ๑) year of diagnosis $(\mathrm{N}=17189)$. In addition, patients with incomplete surgery history data, non-adenocarcinomatous histologies, non-specified AJCC stage and not specified or AJCC stage $=0$ were excluded from our analyses (Figure 1). The primary endpoint of this study was CRC-specific survival (CCSS). The death of CRC patients was categorized as CRC-specific or nonCRC-related. CCSS of CRC-specific death was calculated from the date of diagnosis to the date of CRC death, whereas non-CRC related deaths were censored at the date of death.

\section{NBF Score, NBF Stage, and Statistical Analysis}

Initially, univariate Cox analysis was conducted to identify all the independent prognostic variables. Subsequently, the prognostic factors with $\mathrm{P}$ value $<0.2$ in the univariate analysis were entered

\section{Colorectal cancer patients aged less than 45 years old at SEER 18 registries between January 1, 2007, and December 31, 2015. \\ $(\mathrm{N}=18354)$}

Exclusions:

1. Non-adenocarcinomatious histologies

2. AJCC stage not specified or AJCC stage $=0$

3. Whether surgery performed was unknown

$(n=2060)$
Colorectal cancer patients with known NBFs:

1. Marital status (married or unmarried) $(\mathrm{N}=17456)$

2. Insurance status (insured, medicaid or uninsured) $(\mathrm{N}=17189)$

3. Median household income

$(\mathrm{N}=17189)$

4. County $\%$ with bachelor degree $(\mathrm{N}=17189)$

5. Unemployment situation

$(\mathrm{N}=17189)$

6. Year of diagnosis $(\mathrm{N}=17189)$
Final Target population: colorectal cancer patients aged less than 45 years old with known NBFs and seventh Edition seventh edition of AJCC TNM stage $(\mathrm{N}=15129)$

FIGURE 1 | Flow diagram of patient selection. 
into the multivariate Cox analyses, including gender, tumor grade, AJCC stage, surgery status, histology, the receipt of chemotherapy and all the NBFs (insurance status, county-level median household income, county \% were unemployed, year of diagnosis, county \% with bachelor degree and marital status), which indicated that only the variables county-level median household income, marital status and insurance status were significantly associated with the cause specific survival in patients before 45 years.

The NBF score was determined according to the results of the multivariate Cox analysis. As shown in Figure 2, we considered the point of each group of each NBF equivalent to the value of the hazard ratios which were generated in multivariate Cox analysis. Subsequently, we assigned each patient a NBF score that was the total of the hazard ratio points in the three NBFs. For instance, a married and insured patient whose county-level median household income was 42.20-51.48 K (dollars) had a calculated score of the sum of "1.000", "1.000", and "1.164" which was equivalent to " 3.164 ". The NBF stage of each patient was subsequently stratified according to the NBF score. It was shown that the total score ranged from 3.000-3.864, which was divided into two groups with the median NBF score of all the CRC patients aged less than 45 years old as the cut-off value (3.227). Patients with lower NBF score were assigned to stage NBF 0 and others with higher NBF score were assigned to NBF 1 (14). The distribution and associations of county-level median household income, marital status and insurance status are presented in Figure 3.

In the present study, Cox proportional hazard regression models were constructed to evaluate the prognosis of different prognostic factors. The hazard ratios (HRs) were shown with 95\% confidence intervals (CIs). Kaplan-Meier method was utilized to compare the prognostic value of different factors with the log-rank test. Only P-values lower than 0.05 were considered to reach statistical significance. Statistical analyses in the present were performed with the Statistical Package for Social Science (SPSS version 23; IBM Corp, Armonk, NY, USA).

\section{RESULTS}

In total, 15,129 patients were identified from the SEER database before 45 years with known NBFs. The median follow-up time was 41 (range, 0-119) months. A total of 3,730 (24.7\%) patients succumbed to $\mathrm{CRC}$ at the end of the follow-up time. The baseline characteristics of the total cohort were summarized, as shown in Table 1.

\section{NBFs Are Significant Prognostic Factors of Patients Before $\mathbf{4 5}$ years}

As shown in Table 2, univariate Cox analyses resulted in the identification of the patient characteristics with $P$ values less than 0.20 . These data were introduced in multivariate Cox analyses. Only county-level median household income, marital status and insurance status were NBFs that were significantly associated with cause-specific survival in CRC patients aged less than 45 years old $(\mathrm{P}<0.05)$. In addition, gender, tumor grade, AJCC stage, surgical status, histology and the receipt of chemotherapy were also found to be independent prognostic factors in CRC patients aged less than 45 years old. The variables including lower county-level median household income, Medicaid, uninsured and unmarried were found to be associated with higher risk of CRC-specific mortality $(\mathrm{P}<0.01)$.

\section{The NBF Stage Was Strongly Associated With the Prognosis of Patients Before 45 Years}

A total of $8,830(58.4 \%)$ patients were assigned to stage NBF 0 and $6,299(41.6 \%)$ patients were assigned to stage NBF 1. Both univariate and multivariate Cox analyses indicated that NBF

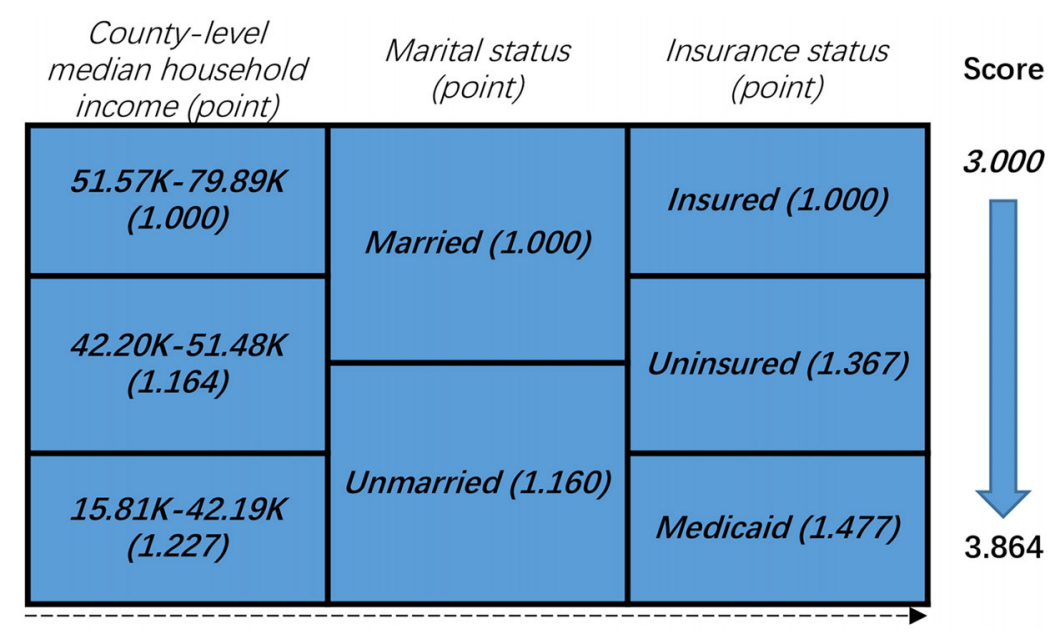

FIGURE 2 | Non-biological factor (NBF) score in colorectal cancer patients younger than 45 years: risk-stratifications. 


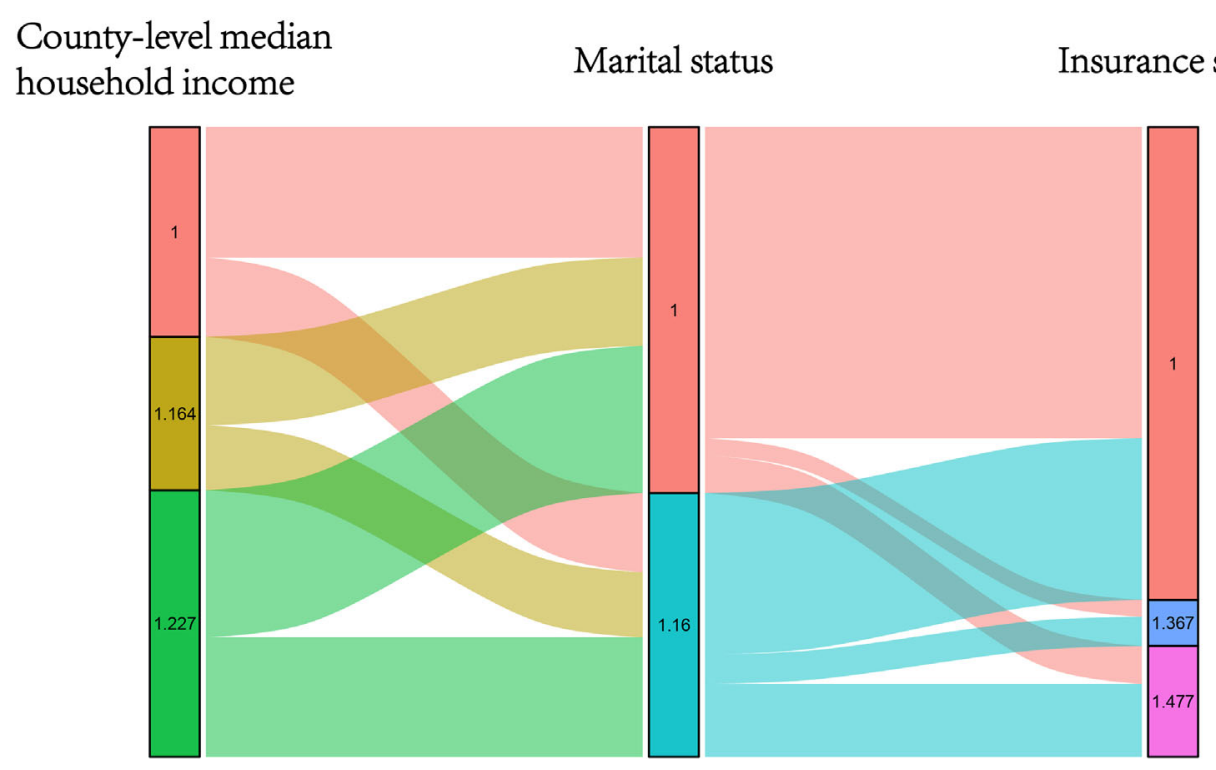

FIGURE 3 | Graphical summary of the distribution and associations of different score subgroups in county-level median household income, insurance status and marital status, respectively.

stage was a strong prognostic factor in CRC patients aged less than 45 years old, whereas stage NBF 1 was independently associated with $50.5 \%$ increased risk of CRC specific mortality $(\mathrm{HR}=1.505,95 \% \mathrm{CI}=1.411-1.606, \mathrm{P}<0.001$; Table 3).

\section{Prognostic Significance of NBF Stage Following the Combination With TNM Stage}

After the combination with NBF stage, each AJCC TNM stage was assigned to stage NBF 0 or stage NBF 1, including I NBF0, I NBF1, IIA NBF0, IIA NBF1, IIB NBF0, IIB NBF1, IIC NBF0, IIC NBF1, IIIA NBF0, IIIA NBF1, IIIB NBF0, IIIB NBF1, IIIC NBF0, IIIC NBF1, IVA NBF0, IVA NBF1, IVB NBF0 and IVB NBF1.

Kaplan-Meier survival analyses indicated that all stage NBF 0 patients were associated with a statistically significant increased CCSS compared to stage NBF 1 patients in different AJCC TNM stages (Figures 4A-C). Moreover, these results were also validated in multivariate Cox analyses as follows: All the stage NBF 0 patients indicated lower HRs compared with the respective stage NBF 1 patients, which was in agreement with the results of the Kaplan-Meier survival analyses.

It should also be noted that several stage NBF 1-TNM patients exceeded stage NBF 0 with higher conventional AJCC TNM stage. For example, the risk of CRC-specific mortality of stage IIB NBF $1(\mathrm{HR}=4.264,95 \% \mathrm{CI}=2.843-6.396$, using stage NBF 1 as the reference, $\mathrm{P}<0.001)$ was significantly higher than that stage IIC NBF $0(\mathrm{HR}=2.988,95 \% \mathrm{CI}=1.611-5.541$, using stage NBF 1 as the reference, $\mathrm{P}=0.001)$. The risk of CRC-specific mortality of stage IIC NBF $1(\mathrm{HR}=5.095,95 \% \mathrm{CI}=3.034-8.556$, using stage NBF 1 as the reference, $\mathrm{P}<0.001)$ was significantly higher than that of stage IIIA NBF $0(\mathrm{HR}=0.967,95 \% \mathrm{CI}=$
$0.580-1.612$, using stage NBF 1 as the reference, $\mathrm{P}=0.898)$ and the risk of CRC-specific mortality of stage IIIA NBF 1 (HR = $2.556,95 \% \mathrm{CI}=1.586-4.121$, using stage NBF 1 as the reference, $\mathrm{P}<0.001$ ) was significantly higher than that of stage IIIB NBF 0 $(\mathrm{HR}=2.191,95 \% \mathrm{CI}=1.584-3.030$, using stage NBF 1 as the reference, $\mathrm{P}<0.001)$. Finally, the risk of CRC-specific mortality of stage IIIB NBF 1 ( $\mathrm{HR}=4.327,95 \% \mathrm{CI}=3.146-5.952$, using stage NBF 1 as the reference, $\mathrm{P}<0.001)$ was significantly higher than that of stage IIIC NBF $0(\mathrm{HR}=4.119,95 \% \mathrm{CI}=3.001-5.651$, using stage NBF 1 as the reference, $\mathrm{P}<0.001$ ), which indicated that stage NBF 1 could increase the diagnostic value of conventional TNM stage (Table 4). In other words, the NBF stage could significantly affect the prognosis of patients younger than 45 years.

\section{DISCUSSION}

The present study demonstrated that NBF stage was strongly related to the prognosis of patients before 45 years, whereas stage NBF 1 was independently associated with $50.5 \%$ increased risk of CRC specific mortality. Following combination with the TNM stage, the results demonstrated that NBF 0 patients were associated with a statistically significant increased CCSS compared to the stage $\mathrm{NBF} 1$ patients in all the respective AJCC TNM stages. It should also be noted that several stages of NBF 1-TNM patients exceeded stage NBF 0 with higher conventional AJCC TNM stage. For example, the risk of CRCspecific mortality of stage IIB NBF 1 patients was significantly higher than that of stage IIC NBF 0 subjects, whereas the risk of CRC-specific mortality of stage IIC NBF 1 patients was 
significantly higher than that of stage IIIA NBF 0 . The risk of CRC-specific mortality of stage IIIA NBF 1 subjects was significantly higher than that of stage IIIB NBF 0 subjects, whereas the risk of CRC-specific mortality of stage IIIB NBF 1 patients was significantly higher than that of stage IIIC NBF 0 patients, indicating that stage NBF 1 could increase the diagnostic value of the conventional TNM stage. In other words, the NBF stage could significantly affect the prognosis of patients younger than 45 years. Therefore, the present findings indicated that the combination of the NBF stage could increase the prognostic value of the TNM stage system. 45 years.

Incidence rates of patients over the age of 55 years have shown a decline during the last several decades. This trend was accelerated in 2000, and this phenomenon would be even more pronounced in adults aged 65 years or older (16). In contrast to these subjects, CRC incidence rates have increased by $1.3 \%$ and $2.3 \%$ per year in patients at the age of 40-49 years in the United States over the last two decades (3). The vast majority of CRCs occurred following the age of 50 . Therefore, the ACS recommended average-risk CRC screening in adults aged $\geq 45$ years with stool-based test or a visual examination. These findings indicate that CRC patients under the age of 45 are still somewhat ignored (4).

NBFs have been demonstrated to contribute to tumor development by previous studies. NBFs may act directly or indirectly to facilitate the consequences of different biological changes, thus affecting the prognostic effect of the biological factors in cancer patients (12).

The present study indicated that three NBFs were significantly associated with the oncological outcomes of CRC prior to 45 years, including county-level median household income, marital status and insurance status. The lower the income, the worse the prognosis of CRC (the income of $51.57 \mathrm{~K}-79.89 \mathrm{~K}$ was used as reference and the income of $15.81 \mathrm{k}-42.19 \mathrm{~K}$ increased the risk of death by $22.7 \%$ compared with the income of $51.57 \mathrm{~K}-79.89 \mathrm{~K})$. The prognostic effect of income on survival in the present study was in agreement with a previous study in ovarian cancer (17). This may be attributed to the fact that low-income patients were less likely to prefer active treatment owing to the fragile financial support network in CRC treatment.

As shown in our previous analyses, in the United States, Medicaid increased the risk of CRC-specific mortality death by $47.7 \%$ compared with that noted in insured patients. We held the view that late initiating treatment, inadequate treatment and poor physical conditions might contribute to the poor prognosis of young CRC patients with Medicaid. Previous studies have reported the prognostic effect of insurance status in many cancers, and Medicaid or uninsured patients would have worse survival compared with insured ones (18-21).

It has been reported in several previous studies that marital status had a prognostic effect on survival of several cancer types including rectal cancers $(11,15,22-25)$. The improved prognosis noted in married CRC patients can be attributed to the improved endocrine, cardiovascular and immune function as well as treatment compliance in married patients (26).
TABLE 1 | Baseline characteristics of colon cancer patients included in our study.

\begin{tabular}{|c|c|}
\hline Characteristic & No. $(\%)$ \\
\hline \multicolumn{2}{|l|}{ Gender } \\
\hline Male & $7947(52.5)$ \\
\hline Female & $7182(47.5)$ \\
\hline \multicolumn{2}{|l|}{ Tumor grade } \\
\hline Grade I & $1001(6.6)$ \\
\hline Grade ॥ & $9915(65.5)$ \\
\hline Grade III & $2692(17.8)$ \\
\hline Grade IV & $425(2.8)$ \\
\hline Unknown & $1096(7.2)$ \\
\hline \multicolumn{2}{|l|}{ AJCC stage } \\
\hline 1 & $2471(16.3)$ \\
\hline$\| \mathrm{A}$ & 2854 (18.9) \\
\hline IIB & $400(2.6)$ \\
\hline$\| \mathrm{C}$ & $208(1.4)$ \\
\hline IIIA & $614(4.1)$ \\
\hline IIIB & $2916(19.3)$ \\
\hline IIIC & $2181(14.4)$ \\
\hline IVA & $2313(15.3)$ \\
\hline IVB & $1172(7.7)$ \\
\hline \multicolumn{2}{|l|}{ Surgery } \\
\hline Surgery not performed & $1125(7.4)$ \\
\hline Surgery performed & $14004(92.6)$ \\
\hline \multicolumn{2}{|l|}{ Histology } \\
\hline Adenocarcinoma & $13483(89.1)$ \\
\hline Mucinous adenocarcinoma & $1306(8.6)$ \\
\hline Signet-ring cell carcinoma & $340(2.2)$ \\
\hline \multicolumn{2}{|l|}{ Chemotherapy } \\
\hline No/unknown & $4865(32.2)$ \\
\hline Yes & $10264(67.8)$ \\
\hline \multicolumn{2}{|c|}{ County $\%$ with bachelor degree } \\
\hline $6.83 \%-26.58 \%$ & $5068(33.5)$ \\
\hline $26.62 \%-35.68 \%$ & 5039 (33.3) \\
\hline $35.83 \%-54.45 \%$ & 5022 (33.2) \\
\hline \multicolumn{2}{|c|}{ County-level median household income $\mathrm{e}^{\#}$} \\
\hline $15.81 \mathrm{~K}-42.19 \mathrm{~K}$ & $6406(42.3)$ \\
\hline $42.20 \mathrm{~K}-51.48 \mathrm{~K}$ & $3685(24.4)$ \\
\hline $51.57 \mathrm{~K}-79.89 \mathrm{~K}$ & 5038 (33.3) \\
\hline \multicolumn{2}{|l|}{ County $\%$ were unemployed } \\
\hline $1.29 \%-5.97 \%$ & $5075(33.5)$ \\
\hline $5.98 \%-7.80 \%$ & $6201(41.0)$ \\
\hline $7.84 \%-17.16 \%$ & $3853(25.5)$ \\
\hline \multicolumn{2}{|l|}{ Year of diagnosis } \\
\hline 2007 & $1624(10.7)$ \\
\hline 2008 & 1656 (10.9) \\
\hline 2009 & 1707 (11.3) \\
\hline 2010 & 1665 (11.0) \\
\hline 2011 & $1651(10.9)$ \\
\hline 2012 & 1607 (10.6) \\
\hline 2013 & $1629(10.8)$ \\
\hline 2014 & $1858(12.3)$ \\
\hline 2015 & $1732(11.4)$ \\
\hline \multicolumn{2}{|l|}{ Insurance status } \\
\hline Insured & $11356(75.1)$ \\
\hline Medicaid & $2664(17.6)$ \\
\hline Uninsured & $1109(7.3)$ \\
\hline \multicolumn{2}{|l|}{ Marital status } \\
\hline Married & $8972(58.1)$ \\
\hline Unmarried & 6337 (41.9) \\
\hline
\end{tabular}

"Shown in US dollars.

Previous studies have proposed the inadequate prognostication of the present AJCC TNM staging system in CRC (27-29). Therefore, in the present study, the implications of 
TABLE 2 | Univariate and multivariable Cox regression analyses of all independent prognostic factors in patients before the recommended initiating colorectal cancer screening age.

\begin{tabular}{|c|c|c|c|c|c|}
\hline \multirow[t]{2}{*}{ Groups } & \multirow[t]{2}{*}{ Variable } & \multicolumn{2}{|c|}{ Univariate analyses } & \multicolumn{2}{|c|}{ Multivariate analyses } \\
\hline & & HR (95\%Cl) & $P$ & HR $(95 \% \mathrm{Cl})$ & $P$ \\
\hline \multirow[t]{3}{*}{ Gender } & & & $<0.001$ & & $<0.001$ \\
\hline & Male & Reference & & Reference & \\
\hline & Female & 0.864 (0.810-0.922) & & $0.845(0.792-0.902)$ & \\
\hline \multirow[t]{6}{*}{ Tumor grade } & & & $<0.001$ & & $<0.001$ \\
\hline & Grade I & Reference & & Reference & \\
\hline & Grade II & $1.344(1.141-1.582)$ & & 1.306 (1.106-1.542) & \\
\hline & Grade III & 3.133 (2.647-3.708) & & 2.255 (1.898-2.680) & \\
\hline & Grade IV & 3.222 (2.579-4.026) & & 2.158 (1.720-2.709) & \\
\hline & Unknown & 2.608 (2.160-3.148) & & 1.550 (1.279-1.879) & \\
\hline \multirow[t]{10}{*}{ AJCC stage } & & & $<0.001$ & & $<0.001$ \\
\hline & I & Reference & & Reference & \\
\hline & IIA & 1.761 (1.389-2.232) & & $1.674(1.317-2.128)$ & \\
\hline & IIB & 5.186 (3.876-6.938) & & 4.485 (3.334-6.034) & \\
\hline & IIC & $5.966(4.048-8.794)$ & & $5.252(3.543-7.784)$ & \\
\hline & IIIA & 1.939 (1.380-2.724) & & $2.076(1.468-2.935)$ & \\
\hline & IIIB & 4.279 (3.455-5.300) & & 4.116 (3.286-5.155) & \\
\hline & IIIC & 8.031 (6.516-9.897) & & 7.098 (5.687-8.859) & \\
\hline & IVA & 26.618 (21.784-32.525) & & 22.369 (18.059-27.707) & \\
\hline & IVB & 41.338 (33.597-50.862) & & 29.702 (23.749-37.148) & \\
\hline \multirow[t]{3}{*}{ Surgery } & & & $<0.001$ & & $<0.001$ \\
\hline & Surgery not performed & Reference & & Reference & \\
\hline & Surgery performed & $0.167(0.154-0.182)$ & & $0.385(0.351-0.423)$ & \\
\hline \multirow[t]{4}{*}{ Histology } & & & $<0.001$ & & $<0.001$ \\
\hline & Adenocarcinoma & Reference & & Reference & \\
\hline & Mucinous adenocarcinoma & $1.371(1.233-1.524)$ & & $1.101(0.987-1.227)$ & \\
\hline & Signet-ring cell carcinoma & $4.183(3.632-4.818)$ & & $1.819(1.567-2.112)$ & \\
\hline \multirow[t]{3}{*}{ Chemotherapy } & & & $<0.001$ & & 0.015 \\
\hline & No/unknown & Reference & & Reference & \\
\hline & Yes & $2.677(2.453-2.921)$ & & $0.888(0.807-0.978)$ & \\
\hline \multirow[t]{4}{*}{ County \% with bachelor degree } & & & $<0.001$ & & 0.072 \\
\hline & $6.83 \%-26.58 \%$ & Reference & & Reference & \\
\hline & $26.62 \%-35.68 \%$ & $0.968(0.897-1.045)$ & & 1.010 (0.924-1.103) & \\
\hline & $35.83 \%-54.45 \%$ & $0.798(0.737-0.864)$ & & $0.909(0.815-1.015)$ & \\
\hline \multirow[t]{4}{*}{ County-level median household income } & & & $<0.001$ & & 0.001 \\
\hline & 51.57K-79.89K & Reference & & Reference & \\
\hline & 42.20K-51.48K & $1.267(1.161-1.382)$ & & $1.164(1.052-1.288)$ & \\
\hline & 15.81K-42.19K & $1.367(1.267-1.476)$ & & $1.227(1.103-1.365)$ & \\
\hline \multirow[t]{4}{*}{ County $\%$ were unemployed } & & & $<0.001$ & & 0.912 \\
\hline & $1.29 \%-5.97 \%$ & Reference & & Reference & \\
\hline & $5.98 \%-7.80 \%$ & $1.160(1.074-1.251)$ & & $0.996(0.914-1.085)$ & \\
\hline & $7.84 \%-17.16 \%$ & $1.267(1.165-1.378)$ & & $0.979(0.881-1.087)$ & \\
\hline \multirow[t]{10}{*}{ Year of diagnosis } & & & 0.458 & & \\
\hline & 2007 & Reference & & & \\
\hline & 2008 & 1.049 (0.929-1.184) & & & \\
\hline & 2009 & 1,082 (0.960-1.221) & & & \\
\hline & 2010 & $0.985(0.868-1.116)$ & & & \\
\hline & 2011 & 1.006 (0.885-1.143) & & & \\
\hline & 2012 & $1.021(0.894-1.165)$ & & & \\
\hline & 2013 & $1.099(0.958-1.260)$ & & & \\
\hline & 2014 & $0.957(0.824-1.111)$ & & & \\
\hline & 2015 & $0.921(0.762-1.113)$ & & & \\
\hline \multirow[t]{4}{*}{ Insurance status } & & & $<0.001$ & & $<0.001$ \\
\hline & Insured & Reference & & Reference & \\
\hline & Medicaid & 1.988 (1.842-2.146) & & 1.477 (1.363-1.600) & \\
\hline & Uninsured & $1.670(1.493-1.869)$ & & $1.367(1.219-1.534)$ & \\
\hline \multirow[t]{3}{*}{ Marital status } & & & $<0.001$ & & $<0.001$ \\
\hline & Married & Reference & & Reference & \\
\hline & Unmarried & $1.440(1.350-1.536)$ & & 1.160 (1.084-1.241) & \\
\hline
\end{tabular}


TABLE 3 | Univariate and multivariable Cox regression analyses of NBF stage and other prognostic factors.

\begin{tabular}{|c|c|c|c|c|c|}
\hline \multirow[t]{2}{*}{ Groups } & \multirow[t]{2}{*}{ Variable } & \multicolumn{2}{|c|}{ Univariate analyses } & \multicolumn{2}{|c|}{ Multivariate analyses } \\
\hline & & HR $(95 \% \mathrm{Cl})$ & $P$ & HR (95\%Cl) & $\boldsymbol{P}$ \\
\hline \multirow[t]{3}{*}{ NBF-stage } & & & $<0.001$ & & $<0.001$ \\
\hline & NBF-stage 0 & Reference & & Reference & \\
\hline & NBF-stage 1 & $1.725(1.618-1.840)$ & & $1.505(1.411-1.606)$ & \\
\hline \multirow[t]{3}{*}{ Gender } & & & $<0.001$ & & $<0.001$ \\
\hline & Male & Reference & & Reference & \\
\hline & Female & $0.864(0.810-0.922)$ & & $0.851(0.798-0.908)$ & \\
\hline \multirow[t]{6}{*}{ Tumor grade } & & & $<0.001$ & & $<0.001$ \\
\hline & Grade I & Reference & & Reference & \\
\hline & Grade II & $1.344(1.141-1.582)$ & & $1.320(1.118-1.559)$ & \\
\hline & Grade III & 3.133 (2.647-3.708) & & $2.271(1.912-2.698)$ & \\
\hline & Grade IV & $3.222(2.579-4.026)$ & & $2.171(1.730-2.724)$ & \\
\hline & Unknown & 2.608 (2.160-3.148) & & $1.570(1.296-1.901)$ & \\
\hline \multirow[t]{10}{*}{ AJCC stage } & & & $<0.001$ & & $<0.001$ \\
\hline & I & Reference & & Reference & \\
\hline & IIA & $1.761(1.389-2.232)$ & & $1.689(1.329-2.148)$ & \\
\hline & IIB & 5.186 (3.876-6.938) & & 4.591 (3.413-6.175) & \\
\hline & IIC & $5.966(4.048-8.794)$ & & $5.331(3.597-7.900)$ & \\
\hline & IIIA & 1.939 (1.380-2.724) & & 2.101 (1.486-2.972) & \\
\hline & IIIB & 4.279 (3.455-5.300) & & 4.167 (3.327-5.219) & \\
\hline & IIIC & 8.031 (6.516-9.897) & & 7.168 (5.743-8.946) & \\
\hline & IVA & $26.618(21.784-32.525)$ & & 22.745 (18.364-28.170) & \\
\hline & IVB & 41.338 (33.597-50.862) & & 30.075 (24.050-37.611) & \\
\hline \multirow[t]{3}{*}{ Surgery } & & & $<0.001$ & & $<0.001$ \\
\hline & Surgery not performed & Reference & & Reference & \\
\hline & Surgery performed & $0.167(0.154-0.182)$ & & $0.383(0.349-0.420)$ & \\
\hline \multirow[t]{4}{*}{ Histology } & & & $<0.001$ & & $<0.001$ \\
\hline & Adenocarcinoma & Reference & & Reference & \\
\hline & Mucinous adenocarcinoma & $1.371(1.233-1.524)$ & & $1.109(0.994-1.236)$ & \\
\hline & Signet-ring cell carcinoma & $4.183(3.632-4.818)$ & & $1.886(1.625-2.189)$ & \\
\hline \multirow[t]{3}{*}{ Chemotherapy } & & & $<0.001$ & & 0.011 \\
\hline & No/unknown & Reference & & Reference & \\
\hline & Yes & $2.677(2.453-2.921)$ & & $0.884(0.803-0.973)$ & \\
\hline
\end{tabular}

NBFs with staging, prognosis and clinical management were assessed in CRC patients before 45 years.

The current study demonstrated that county-level median household income, marital status and insurance status were significantly associated with cause-specific survival in CRC patients younger than 45 years. NBFs were often neglected in clinical practice and patients with poor NBFs deserved more attention and a more intense treatment. The present study indicated that NBF stage was strongly related to the prognosis of patients. Following combination with the TNM stages, NBF 0 patients were associated with a statistically significant increased CCSS compared to the stage NBF 1 patients in all the respective AJCC TNM stages. Therefore, the present study findings indicated that the combination of the NBF stage could increase the prognostic value of the TNM stage.

The present study aimed to increase the information regarding CRC patients younger than 45 years, as well as analyze the NBFs that significantly affect the prognosis of CRC patients, including only county-level median household income, marital status and insurance status. NBFs should arouse sufficient attention of us in clinical practice of patients younger than 45 years. In such way, the research focus on these aspects will be enhanced by the scientific community.
Several limitations of this study should be addressed. Firstly, our analyses were only based on a US population. In the future, therefore, a validation study should be carried out. In the validation study, patients could be from countries beyond the United States. In addition, the validation study could investigate the prognostic value of NBFs in older CRC patients who were not included in the present study, which might lead to other interesting conclusions. And analyses could also be conducted based on different stratification factors such as gender, race and tumor stage. Above all, recruited patients should have complete information of NBFs including individual income, education, insurance, marital status and employment status. Secondly, some prognostic factors were not available in the SEER database and they were not included in our analyses, such as serum biomarkers, family history, microsatellite instability status, ras mutation and braf v600e status (30-32). Finally, the analyses were merely based on retrospective data, which would cause inevitable bias.

\section{CONCLUSION}

County-level median household income, marital status and insurance status were significantly associated with cause-specific 
A

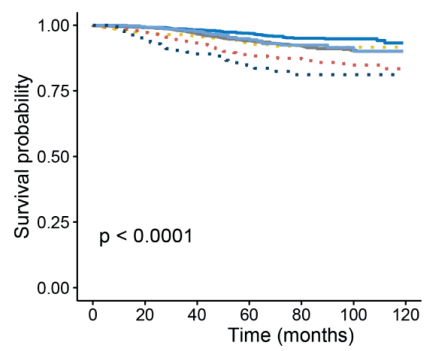

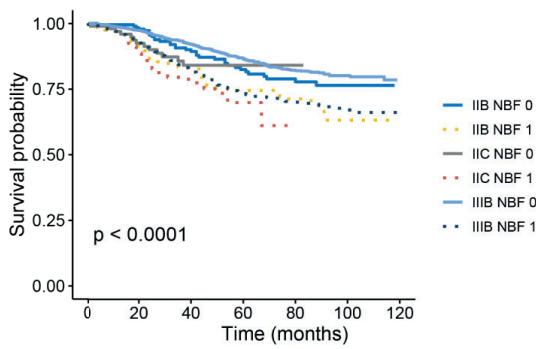

C

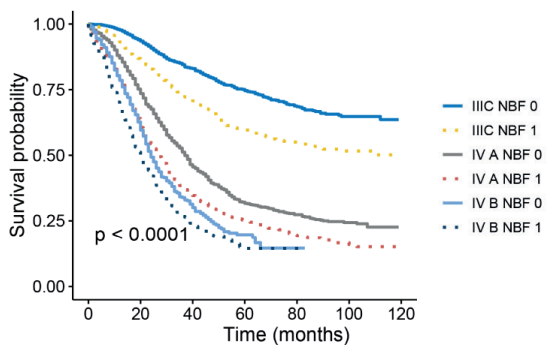

FIGURE 4 | Kaplan-Meier survival curves of NBF-TNM staging system. (A) Cancer-specific survival (CSS) of I-NBF 0 stage, I- NBF 1 stage, IIA-NBF 0 stage, IIANBF 1 stage, IIIA- NBF 0 stage, and IIIA- NBF 1 stage. (B) CSS of IIB- NBF 0 stage, IIB- NBF 1 stage, IIC- NBF 0 stage, IIC- NBF 1 stage, IIIB- NBF 0 stage, and IIIB- NBF 1 stage. (C) CSS of IIIC- NBF 0 stage, IIIC- NBF 1 stage, IVA- NBF 0 stage, IVA- NBF 1 stage, IVB- NBF 0 stage, and IVB- NBF 1 stage.

TABLE 4 | Prognosis of NBF-stage and TNM stage in patients before the recommended initiating colorectal cancer screening age.

\begin{tabular}{|c|c|c|c|c|c|c|c|c|c|}
\hline \multicolumn{5}{|c|}{ AJCC TNM staging system } & \multicolumn{5}{|c|}{ TNM-C staging system } \\
\hline \multirow[t]{2}{*}{ Stage } & \multirow{2}{*}{$\begin{array}{l}\text { Number of } \\
\text { the patients }\end{array}$} & \multicolumn{3}{|c|}{ Cancer-specific survival } & \multirow[t]{2}{*}{ Stage } & \multirow{2}{*}{$\begin{array}{l}\text { Number of } \\
\text { the patients }\end{array}$} & \multicolumn{3}{|c|}{ Cancer-specific survival } \\
\hline & & HR (95\% Cl) & SE & $P$ value & & & HR (95\% Cl) & SE & $P$ value \\
\hline \multirow[t]{2}{*}{ I } & 2471 & Reference & 1 & 1 & I NBFO & 1647 & 0.562 (0.381-0.829) & 0.198 & 0.004 \\
\hline & & & & & I NBF1 & 824 & Reference & $\backslash$ & $\backslash$ \\
\hline \multirow[t]{2}{*}{ IIA } & 2854 & 1.689 (1.329-2.148) & 0.122 & $<0.001$ & IIA NBFO & 1702 & $0.941(0.663-1.335)$ & 0.178 & 0.733 \\
\hline & & & & & IIA NBF1 & 1152 & $1.668(1.181-2.357)$ & 0.176 & 0.004 \\
\hline \multirow[t]{2}{*}{ IIB } & 400 & $4.591(3.413-6.175)$ & 0.151 & $<0.001$ & IIB NBFO & 202 & $2.691(1.718-4.215)$ & 0.229 & $<0.001$ \\
\hline & & & & & IIB NBF1 & 198 & 4.264 (2.843-6.396) & 0.207 & $<0.001$ \\
\hline \multirow[t]{2}{*}{ IIC } & 208 & $5.331(3.597-7.900)$ & 0.201 & $<0.001$ & IIC NBFO & 101 & $2.988(1.611-5.541)$ & 0.315 & 0.001 \\
\hline & & & & & IIC NBF1 & 107 & 5.095 (3.034-8.556) & 0.264 & $<0.001$ \\
\hline \multirow[t]{2}{*}{ IIIA } & 614 & 2.101 (1.486-2.972) & 0.177 & $<0.001$ & IIIA NBFO & 415 & $0.967(0.580-1.612)$ & 0.261 & 0.898 \\
\hline & & & & & IIIA NBF1 & 199 & $2.556(1.586-4.121)$ & 0.244 & $<0.001$ \\
\hline \multirow[t]{2}{*}{ IIIB } & 2916 & 4.167 (3.327-5.219) & 0.115 & $<0.001$ & IIIB NBFO & 1713 & 2.191 (1.584-3.030) & 0.165 & $<0.001$ \\
\hline & & & & & IIIB NBF1 & 1203 & 4.327 (3.146-5.952) & 0.163 & $<0.001$ \\
\hline \multirow[t]{2}{*}{ IIIC } & 2181 & 7.168 (5.743-8.946) & 0.113 & $<0.001$ & IIIC NBFO & 1223 & 4.119 (3.001-5.651) & 0.161 & $<0.001$ \\
\hline & & & & & IIIC NBF1 & 958 & $6.829(4.985-9.356)$ & 0.161 & $<0.001$ \\
\hline \multirow[t]{2}{*}{ IVA } & 2313 & 22.745 (18.364-28.170) & 0.109 & $<0.001$ & IVA NBF0 & 1241 & $14.300(10.554-19.374)$ & 0.155 & $<0.001$ \\
\hline & & & & & IVA NBF1 & 1072 & 19.819 (14.615-26.878) & 0.155 & $<0.001$ \\
\hline \multirow[t]{2}{*}{ IVB } & 1172 & 30.075 (24.050-37.611) & 0.114 & $<0.001$ & IVB NBF0 & 586 & 20.162 (14.712-27.630) & 0.161 & $<0.001$ \\
\hline & & & & & IVB NBF1 & 586 & 24.939 (18.215-34.146) & 0.160 & $<0.001$ \\
\hline
\end{tabular}

survival in CRC patients younger than 45 years. The present study showed that NBF stage was strongly related to the prognosis of patients. Following combination with the TNM stages, NBF 0 patients were associated with a statistically significant increased CCSS compared to the stage NBF 1 patients in all the respective
AJCC TNM stages, indicating the combination of the NBF stage could increase the prognostic value of the TNM stage. Staging45 years NBFs should not be neglected in clinical practice and patients with poor NBFs deserved more attention and more intense treatment of CRC patients before 45 years. 


\section{DATA AVAILABILITY STATEMENT}

Publicly available datasets were analyzed in this study. This data can be found here: https://seer.cancer.gov/data/ access.html.

\section{ETHICS STATEMENT}

The study was approved by the Ethical Committee and Institutional Review Board of the Fudan University Shanghai Cancer Center. The data did not include the use of human subjects or personal identifying information and no informed consent was required for this study.

\section{REFERENCES}

1. Kuipers EJ, Grady WM, Lieberman D, Seufferlein T, Sung JJ, Boelens PG, et al. Colorectal Cancer. Nat Rev Dis Primers (2015) 1:15065. doi: 10.1038/ nrdp. 2015.65

2. Ahnen DJ, Patel SG. Cost-Effectiveness and National Effects of Initiating Colorectal Cancer Screening for Average-Risk Persons at Age 45 Years Instead of 50 Years. Gastroenterology (2019) 157:1691-2. doi: 10.1053/ j.gastro.2019.04.056

3. Ladabaum U, Mannalithara A, Meester RGS, Gupta S, Schoen RE. CostEffectiveness and National Effects of Initiating Colorectal Cancer Screening for Average-Risk Persons at Age 45 Years Instead of 50 Years. Gastroenterology (2019) 157:137-48. doi: 10.1053/j.gastro.2019.03.023

4. Wolf AMD, Fontham ETH, Church TR, Flowers CR, Guerra CE, LaMonte SJ, et al. Colorectal Cancer Screening for Average-Risk Adults: 2018 Guideline Update From the American Cancer Society. CA: A Cancer J For Clin (2018) 68:250-81. doi: 10.3322/caac.21457

5. Gomez SL, Hurley S, Canchola AJ, Keegan TH, Cheng I, Murphy JD, et al. Effects of Marital Status and Economic Resources on Survival After Cancer: A Population-Based Study. Cancer (2016) 122:1618-25. doi: 10.1002/cncr.29885

6. Pisu M, Kenzik KM, Oster RA, Drentea P, Ashing KT, Fouad M, et al. Economic Hardship of Minority and non-Minority Cancer Survivors 1 Year After Diagnosis: Another Long-Term Effect of Cancer? Cancer (2015) 121:1257-64. doi: 10.1002/cncr.29206

7. Varlotto JM, Voland R, McKie K, Flickinger JC, DeCamp MM, Maddox D, et al. Population-Based Differences in the Outcome and Presentation of Lung Cancer Patients Based Upon Racial, Histologic, and Economic Factors in All Lung Patients and Those With Metastatic Disease. Cancer Med (2018) 7:1211-20. doi: 10.1002/cam4.1430

8. Goodwin JS, Hunt WC, Key CR, Samet JM. The Effect of Marital Status on Stage, Treatment, and Survival of Cancer Patients. Jama (1987) 258:3125-30. doi: 10.1001/jama.258.21.3125

9. Wang CC, Yang CC, Yeh SA, Huang CI, Hwang TZ, Yang CC, et al. The Impact of Insurance and Marital Status on Survival in Patients With Nasopharyngeal Carcinoma. Biol (Basel) (2020) 9(4):84. doi: 10.3390/ biology9040084

10. Loya A, Ayaz T, Weng CY. Impact of Marital Status on Survival in Patients With Ocular and Periocular Malignancies: A Retrospective Analysis of 3159 Patients From the SEER Database. Clin Ophthalmol (2020) 14:1127-33. doi: $10.2147 /$ OPTH.S238034

11. Simpson MC, Challapalli SD, Cass LM, Zahirsha ZS, Adjei Boakye E, Massa ST, et al. Impact of Gender on the Association Between Marital Status and Head and Neck Cancer Outcomes. Oral Oncol (2019) 89:48-55. doi: 10.1016/ j.oraloncology.2018.12.009

12. Danforth DN. Disparities in Breast Cancer Outcomes Between Caucasian and African American Women: A Model for Describing the Relationship of Biological and Nonbiological Factors. Breast Cancer Res BCR (2013) 15:208. doi: $10.1186 /$ bcr3429

\section{AUTHOR CONTRIBUTIONS}

QGL and XL conceptualized and designed the study. QL and RZ conducted the analyses of the study. QL interpreted the data. QL and RZ drafted the manuscript. QL revised the manuscript. All authors contributed to the article and approved the submitted version.

\section{FUNDING}

This research was supported by the National Science Foundation of China (No. 81772599, 81972260 and 81702353) and Shanghai Municipal Natural Science Foundation (17ZR1406400). The funders had no role in the study design, data collection and analysis, decision to publish, or preparation of the manuscript.

13. Huang Y, Sheng H, Zhang J, Liu Q, Ye D, Shi G. Incorporating Non-Biological Factors Into the TNM Staging System for Better Prognostication and Decision-Making in Testicular Cancer. World J Urol (2019) 37:2165-73. doi: 10.1007/s00345-018-2603-1

14. Liu Q, Luo D, Cai S, Li Q, Li X. Real-World Implications of Nonbiological Factors With Staging, Prognosis and Clinical Management in Colon Cancer. Cancers (2018) 10(8):263. doi: 10.3390/cancers 10080263

15. Li Q, Gan L, Liang L, Li X, Cai S. The Influence of Marital Status on Stage at Diagnosis and Survival of Patients With Colorectal Cancer. Oncotarget (2015) 6:7339-47. doi: 10.18632/oncotarget.3129

16. Vekic B, Dragojevic-Simic V, Jakovljevic M, Kalezic M, Zagorac Z, Dragovic S, et al. A Correlation Study of the Colorectal Cancer Statistics and Economic Indicators in Selected Balkan Countries. Front Public Health (2020) 8:29. doi: 10.3389/fpubh.2020.00029

17. Cowan RA, Tseng J, Ali N, Dearie H, Murthy V, Gennarelli RL, et al. Exploring the Impact of Income and Race on Survival for Women With Advanced Ovarian Cancer Undergoing Primary Debulking Surgery at a HighVolume Center. Gynecol Oncol (2018) 149:43-8. doi: 10.1016/j.ygyno. 2017.11.012

18. Groth SS, Al-Refaie WB, Zhong W, Vickers SM, Maddaus MA, D'Cunha J, et al. Effect of Insurance Status on the Surgical Treatment of Early-Stage NonSmall Cell Lung Cancer. Ann Thorac Surg (2013) 95:1221-6. doi: 10.1016/ j.athoracsur.2012.10.079

19. Chen Z, Gao W, Pu L, Zhang L, Han G, Zhu Q, et al. Impact of Insurance Status on the Survival of Gallbladder Cancer Patients. Oncotarget (2017) 8:51663-74. doi: 10.18632/oncotarget.18381

20. Takenaka Y, Yasui T, Enomoto K, Miyabe H, Morizane N, Ashida N, et al. Health Insurance Status and Survival Among Patients With Head and Neck Cancer in Japan. Int J Clin Oncol (2016) 21:517-22. doi: 10.1007/s10147-0150921-5

21. Markt SC, Tang T, Cronin AM, Katz IT, Howitt BE, Horowitz NS, et al. Insurance Status and Cancer Treatment Mediate the Association Between Race/Ethnicity and Cervical Cancer Survival. PLoS One (2018) 13:e0193047. doi: 10.1371/journal.pone.0193047

22. Mao W, Zhang Z, Huang X, Fan J, Geng J. Marital Status and Survival in Patients With Penile Cancer. J Cancer (2019) 10:2661-9. doi: 10.7150/ jca.32037

23. Wu S-G, Zhang Q-H, Zhang W-W, Sun J-Y, Lin Q, He Z-Y. The Effect of Marital Status on Nasopharyngeal Carcinoma Survival: A Surveillance, Epidemiology and End Results Study. J Cancer (2018) 9:1870-6. doi: $10.7150 /$ jca. 23965

24. Bai D-S, Chen P, Qian J-J, Jin S-J, Jiang G-Q. Effect of Marital Status on the Survival of Patients With Gallbladder Cancer Treated With Surgical Resection: A Population-Based Study. Oncotarget (2017) 8:26404-13. doi: 10.18632/oncotarget.15476

25. Miao T, Li Y, Sheng X, Yao D. Marital Status and Survival of Patients With Kidney Cancer. Oncotarget (2017) 8:86157-67. doi: 10.18632/oncotarget. 21029 
26. Iwashyna TJ, Christakis NA. Marriage, Widowhood, and Health-Care Use. Soc Sci Med (2003) 57:2137-47. doi: 10.1016/S0277-9536(02)00546-4

27. Weiser MR, Gönen M, Chou JF, Kattan MW, Schrag D. Predicting Survival After Curative Colectomy for Cancer: Individualizing Colon Cancer Staging. J Clin Oncol (2011) 29:4796-802. doi: 10.1200/JCO.2011.36.5080

28. Auclin E, Zaanan A, Vernerey D, Douard R, Gallois C, Laurent-Puig P, et al. Subgroups and Prognostication in Stage III Colon Cancer: Future Perspectives for Adjuvant Therapy. Ann Oncol (2017) 28:958-68. doi: 10.1093/annonc/mdx030

29. Liu Q, Ma Y, Luo D, Cai S, Li Q, Li X. Real-World Study of a Novel Prognostic Scoring System: for a More Precise Prognostication and Better Clinical Treatment Guidance in Stages II and III Colon Cancer. Int J Colorectal Dis (2018) 33:1107-14. doi: 10.1007/s00384-018-3071-1

30. Liu Q, Luo D, Cai S, Li Q, Li X. Circulating Basophil Count as a Prognostic Marker of Tumor Aggressiveness and Survival Outcomes in Colorectal Cancer. Clin Transl Med (2020) 9:6. doi: 10.1186/s40169-019-0255-4

31. Rowland A, Dias MM, Wiese MD, Kichenadasse G, McKinnon RA, Karapetis CS, et al. Meta-Analysis of BRAF Mutation as a Predictive Biomarker of
Benefit From Anti-EGFR Monoclonal Antibody Therapy for RAS Wild-Type Metastatic Colorectal Cancer. Br J Cancer (2015) 112:1888-94. doi: 10.1038/ bjc. 2015.173

32. Gupta R, Sinha S, Paul RN. The Impact of Microsatellite Stability Status in Colorectal Cancer. Curr Probl Cancer (2018) 42:548-59. doi: 10.1016/ j.currproblcancer.2018.06.010

Conflict of Interest: The authors declare that the research was conducted in the absence of any commercial or financial relationships that could be construed as a potential conflict of interest.

Copyright (C) $2021 \mathrm{Liu}$, Zhang, Li and Li. This is an open-access article distributed under the terms of the Creative Commons Attribution License (CC BY). The use, distribution or reproduction in other forums is permitted, provided the original author(s) and the copyright owner(s) are credited and that the original publication in this journal is cited, in accordance with accepted academic practice. No use, distribution or reproduction is permitted which does not comply with these terms. 